\title{
LA NECRÓPOLIS ROMANA ALTO-IMPERIAL DEL «PARQUE DE LAS NACIONES» (ALBUFERETA, ALICANTE): ESTUDIO DE ALGUNO DE SUS MATERIALES
}

\author{
PABLO ROSSER LIMIÑANA \\ Ayuntamiento de Alicante
}

\begin{abstract}
Una excavación de salvamento y el estudio de materiales de colecciones particulares han permitido conocer importantes aspectos de una necrópolis romana del Alto Imperio, entre los que destaca de manera especial la perduración de varios tipos de cerámica ibérica.

A rescue excavation and the study of materials from private collections have allowed to know important aspects of a Roman necropolis from the Early Empire, especially the perdurance of several types of Iberic pottery.
\end{abstract}

La entrega al COPHIAM, por parte de unos coleccionistas, de una serie de material arqueológico aparecido en las inmediaciones de la urbanización «Parque de las Naciones», y las referencias dadas por los mismos en relación a la existencia de huesos calcinados y cenizas en el interior de las urnas encontradas, nos alertaron sobre la posible existencia de una necrópolis de importancia y extensión difíciles de conocer en ese momento.

Por esas mismas fechas, y dentro de una excavación de urgencia practicada por el COPHIAM en un solar situado a unos 200 metros al oeste del anterior, se documentó una necrópolis romana cuyo material exhumado se asemejaba sobremanera al entregado a nosotros por dichos coleccionistas. Este segundo hecho nos reafirmó en la hipótesis de la existencia de una zona de enterramiento en el punto antes indicado (ROSSER LIMINAÑA, P., 1989).
Con independencia de las excavaciones que el COPHIAM ha iniciado en ambos sitios, cuyos resultados se publicarán en su momento, nos ha parecido interesante estudiar el material que tan gentilmente nos proporcionaron las personas indicadas. De ese modo, se saca a la luz unas piezas que aunque no cuentan con el inestimable apoyo de la secuencia estratigráfica proporcionada por el método arqueológico, sí puede ofrecer una primera aproximación al estudio de las necrópolis alto-imperiales, poco conocidas en la arqueología romana de las tierras valencianas.

No obstante, como ya hemos comentado, la investigación de los materiales que aparezcan en las excavaciones en curso, completarán de una manera importante el estudio que ahora presentamos. 


\section{LOCALIZACIÓN}

La Albufereta de Alicante es una zona de gran importancia arqueológica, toda vez que sobre el monte conocido con el nombre Tossal de Manises se asentó una población ibérica, cuya ciudad fue posteriormente integrada al Imperio Romano. Esta circunstancia produjo el que en las inmediaciones de este monte aparecieran una serie de asentamientos más o menos dispersos y con funciones bien diversas. Dentro de este contexto hay que situar, sin duda, a las necrópolis o lugares de enterramiento, que como es ampliamente sabido, en el mundo romano se encontraban a las afueras de las ciudades, normalmente junto a vías de acceso a aquéllas.

La necrópolis que ahora nos ocupa se encontraba situada, por tanto, al exterior de la urbe, sin que podamos saber su extensión real debido a la intensa actividad edilicia que desde los años sesenta ha sufrido la zona, debastando cualquier indicio de ocupación anterior. Por la misma circunstancia, se nos hace difícil recomponer topográfica y urbanísticamente la zona en cuestión, aunque no cabe duda que teniendo en cuenta la aparición de la otra necrópolis comentada (del «Fapegal») a tan sólo unos cientos de metros, hay que pensar que estamos ante una amplia zona de enterramientos. Su explicación quizá haya que buscarla en la orientación de la puerta de la ciudad, en frente de la cual se hallan las necrópolis.

El lugar concreto del hallazgo se caracteriza por su mínima potencia estratigráfica, apareciendo la roca madre a escasa profundidad de la superficie. Los restos de la necrópolis del «Parque de las Naciones», normalmente aparecen por debajo de estructuras de habitación, que hay que pensar que son más tardías, cuya verificación esperamos del estudio de los materiales de una excavación que el Museo Arqueológico Provincial realizó hace ya algunos años en la zona, a cargo de E. Llobregat y J. Uroz.

\section{EL ESTUDIO DE LOS ENTERRAMIENTOS Y SUS MATERIALES}

El grupo de materiales que presentamos en este trabajo, pertenecen al menos a seis tumbas de incineración. Esta agrupación, así como las someras descripciones que expondremos de cada una de ellas deben tomarse en reserva, toda vez que nos han si-

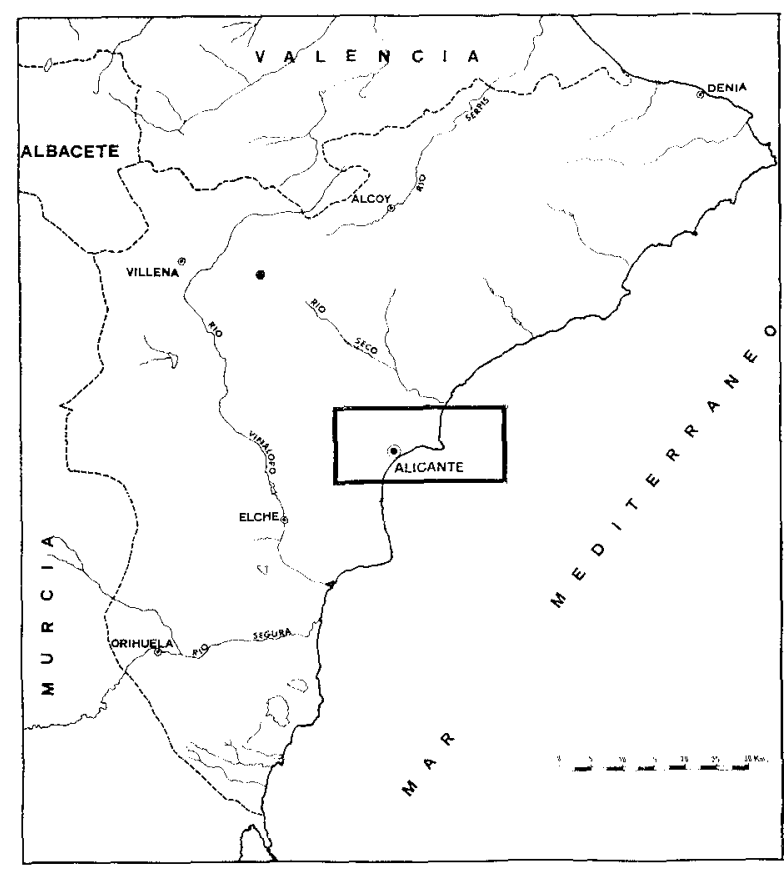

Fig. 1.

do transmitidas oralmente, sin que medie ningún tipo de estratigrafía, foto, etc.

\section{Tumba 1}

Situada bajo el muro de una estancia industrial, posiblemente un pequeño torcularium (apareció un contrapeso de piedra). Sobre la roca aparecieron pequeños fragmentos de huesos calcinados y cenizas.

Materiales:

- URNA FUNERARIA: el uso de las ollas o urnas como contenedoras de las cenizas del difunto está atestiguado en varias necrópolis romanas, en un arco cronológico comprendido entre los inicios del siglo I d. C., hasta fines del siglo II d. C. (SACCARDO, 1985, 470).

En la tumba que nos ocupa apareció una urna con las cenizas del difunto en su interior. Se trata de una olla con borde vuelto hacia afuera (VEGAS 1,11 , fig. 1 y 2) y acanaladura en su interior para la tapadera, boca ancha, cuerpo piriforme y base rehundida (característica de las urnas funerarias de algunas necrópolis peninsulares, como por ejemplo Baelo: REMESAL, 1979, 37, y Baria: ALMAGRO, 1984, 210, fig., 202); el barro es gris y la superficie rugosa. 


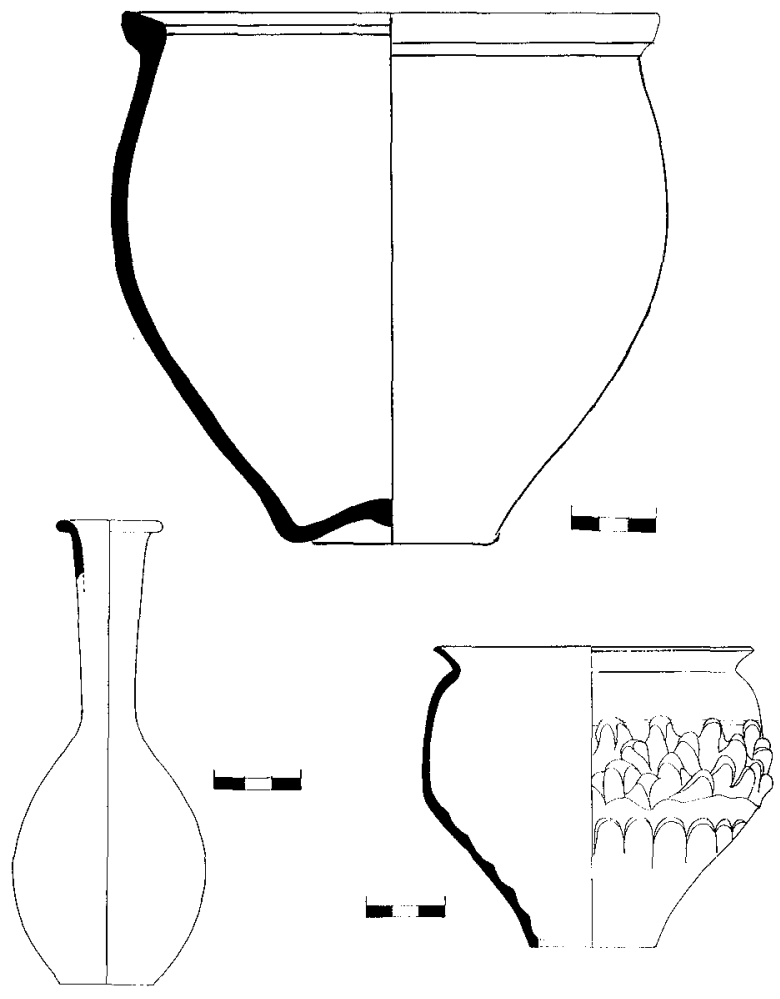

Fig. 2.- Tumba 1.

Aparecen ejemplos de este tipo de urnas funerarias en Ampurias, en donde la encontrada en Alicante podría tener su paralelo en el tipo VIII (urnas simples ovoides, muchas con acanaladura interior en el borde del cuello), y más concretamente con la aparecida en la incineración Patel $n .^{\circ} 5$, fechada en época de Tiberio-Clauido (ALMAGRO, 1955, 39).

Por su parte, en la tumba 5 de Baelo (Op. cit. 21, fig. 9), aparece una urna de forma globular y base rehundida, sin cuello, cuya pasta es, como la de Alicante, gris. Según la tipología de urnas presentada por Remesal, la de la 5 se adscribía al tipo IIc (con el diámetro máximo en la mitad superior de la pieza) y su cronología, por el resto del ajuar, sería de época de Claudio.

De la tipología planteada en la necrópolis de Baria, pertenece al grupo II, sin que podamos precisar a qué olla concreta, debido a su gran diversidad.

- UNGÜENTARIOS: se trata de unos portaperfumes de arcilla (los italianos los denominan balsamari fittili), que si bien en las dos necrópolis de Alicante son abundantes, no siempre aparecen bien representados en otras (PASSI, 1987, 179).
Se trata de un contenedor de líquidos caracterizado por su pequeña abertura, largo cuello y paredes redondeadas, variando su base de plana a fusiforme. Su función era la de contener ungüentos perfumados, por lo que era usado en el tocador y constituía uno de los elementos fundamentales en el mundo funerario.

No se conoce el nombre latino preciso con el cual denominaban los romanos a este tipo de recipientes; no obstante el término unguentarium viene usado en las fuentes históricas para indicar un vaso con aceite perfumado (AUG. EPIST. 158, 12).

Como se ha indicado más arriba, este recipiente es abundante entre el ajuar tanto de la necrópolis de Fapegal, como en la del Parque de las Naciones, que ahora estudiamos.

Son dos los tipos aparecidos en las necrópolis alicantinas:

- Tipo 1: ungüentario fusiforme.

- Tipo 2: ungüentario de cuerpo redondeado y base plana,

de los cuales, en la tumba que ahora estudiamos, se registra sólo un ejemplar, que debe ser adscrito al tipo 2 de los expuestos.

Se trata de un recipiente de arcilla de color ocre (la homogeneidad de la pasta es una característica de los ungüentarios), sin pie y con base plana, de cuerpo piriforme-redondeado y cuello alargado progresivamente hacia su superficie. Borde en forma de bastoncillo, presentando un engobe color sangre (marrón-negruzco) en el borde ỳ cuello, tanto en su parte interior como exterior.

Pertenece, por tanto, al tipo VEGAS 63b (fig. $58, \mathrm{n} .{ }^{\circ} 6,7$ y 8 ), que en otras tipologías se ha denominado como HALTERN 31 (LOESCHCKE, 1909, 103), BARIA VI-1 (ALMAGRO GORBEA, 1984, 209), NAVE 3 (PASSI, 1987, 179, TAV. 23,3), GRATALOUP LXXXb (GRATALOUP, 1988, n. ${ }^{\circ}$ 268 A 272, 180), OBERANDEN 29 (LOESCHCKE, 1942), y que se inspira en ungüentarios realizados en vidrio, forma ISINGS 8.

Es este tipo muy conocido en los contextos arqueológicos, por lo que sus paralelos son abundantes: necrópolis de Ampurias (MARTÍN ALMAGRO, 1955), de Gropello Cairoli (FORTUNATI ZUCCALA, 1979, 5-88), de Mandona di Intimiano (BIANCHI, 1971, 151), de Nave (PASSI, 1987), Mulva II (VEGAS, 1988, BAND, 15), Vindomissa (ETTLINGER-SIMONETT, 1952), Gabii (VEGAS, 1968, 13), Leiden (HOLWERDA, 1936), Ostia (OSTIA II, estrato VA2 + VB, lam. 14, 191-1939), Co- 
rinto (THOMPSON, 1934), Baria (ALMAGRO GORBEA, 1984, 209), Río Miel (RODRÍGUEZ OLIVA, 1977, 347), Pollentia (ARRIBAS, TARRADELL, WOODS, 1973, calle porticada, cuadro III, nivel I, fig. 39, 11), etc.

Cronológicamente, este recipiente se adscribe a contextos de mediados del siglo I a. C., llegando su difusión hasta mediados del I d. C. (ROSSIGNANI, 1973, 335). Así, lo encontramos en Ampurias, formando parte de tumbas de época augustea a claudia; en Corinto, aparece en los niveles anteriores a la reedificación de la ciudad en el año 44 a. C.; en Baria, en una tumba de época de Augusto. Sin embargo, ya no aparece, por ejemplo en la Casa NW de Pollentia, lo que confirma su desaparición a mediados del siglo primero de la era.

Su aparición en el estrato VA2 + VB de Ostia II, fechado en época flavia, se explica por ser un nivel de residuos de época anterior.

- PAREDES FINAS: este tipo de cerámica ocupa una posición importante en el contexto material de las necrópolis romanas alto-imperiales. $\mathrm{Su}$ cronología, más o menos limitada a unas épocas muy concretas, facilitan sobremanera la datación de una tumba.

La característica más evidente de esta cerámica es el espesor particularmente fino de sus paredes, que denota una notable habilidad en su elaboración.

Solamente se ha constatado la existencia de dos recipientes de estas características. Se trata, el primero, de un vasito ovoide, de un tamaño superior al resto de losvasos de paredes finas; presenta un borde inclinado hacia afuera y base plana, con decoración a la barbotina en la parte más ancha del cuerpo de la pieza, y bajo dos finas ranuras, formada por pedúnculos. Barro color avellana, fino, presentando en sus paredes una ligera capa de barniz marrón con matices dorados. Aunque pudiera llevar asa, el hallarse fragmentada la pieza, nos impide asegurarlo.

Se trata de la forma MAYET XLII (MAYET, 1975, pl. LX, 150), GRATALOUP LXV (GRATALOUP, 1988, 97 y 196, n. ${ }^{\circ} 240$ ) y VEGAS 31 (VEGAS, 1973 , 76, fig. 25, 10-11), típica de las producciones ibéricas. Esta pieza se adscribe normalmente a la $2 .^{\text {a }}$ mitad del siglo I d. C. (Claudio-Nerón): tumba $\mathrm{C} 1$ de la necrópolis de Raqqada (ENNABLI, MAHJOUBI, SALOMONSON, 1970, 72, pl. XLVI); Albintimilium (LAMBOGLIA, 1950, 121, fig. 62, n. $^{\circ} 33$ de época flavia, 122, n. $^{\circ} 33$ de Claudio-Nerón); Valencia (MARTÍN ÁVILA, 1963,
$94, n .^{\circ} 27$, de época claudio-neroniana); cementerio de «oficiales» en Cartago (DU COUDRAY, LA BLANCHERE, GAUCKLER, 1897, 234, n. ${ }^{\circ} 188$, pl. XLII); Cavaillon (DUMOULIN, 1965, 7, fig. 7, a.b.); Ostia (OSTIA II, lam. 13, 172: nivel V de época flavia); Río Tinto (MAYET, 1970, 143, lam. 2, 6-8), etc.

En la provincia de Alicante, conocemos al menos dos paralelos: uno en la ciudad del Tossal de Manises, a unos centenares de metros de la necrópolis que ahora estudiamos, en el cual tampoco aparece el asa (MAYET, 1975, fig. LXI, n. ${ }^{\circ} 485$ ); el otro en el Portus Illicitanus (SÁNCHEZ, BLASCO, GUARDIOLA, 1986, fig. 30, 4).

La otra pieza aparecida en la tumba 1, se engloba dentro del conjunto de los vasitos de paredes finas con decoración de hojas de agua (VEGAS 35: 85 , fig. 28), que esta autora fecha en la segunda mitad del siglo I d. C.

Se trata de un bol o copita hemiesférica con dos asas verticales enfrentadas, doble moldura en el borde, paredes más o menos carenadas con un ligero engobe marrón-amarillento y base plana. Esta forma ha sido definida por Mayet como del tipo XXXII, siendo para Grataloup la forma XII de su tipología.

Cronológicamente, Mayet cree que aunque variando según las zonas, puede englobarse esta forma cerámica entre la época de Tiberio y la Flavia (MAYET, 1975, 64, pl. XXXII), situando su apogeo entre Claudio y Nerón. Por su parte, Grataloup fecha esta forma entre los años 30 y $40 \mathrm{~d}$. C. (43, n. ${ }^{\circ} 107$ y 108 ).

\section{Tumba 2}

Al parecer, se localizaba cerca del pequeño torcularium de época posterior. Su ajuar recuperado es muy escaso pero interesante.

Materiales:

- URNA FUNERARIA (?): se trata de una urna fragmentada, a la que le falta parte del cuerpo y la totalidad de la base (diámetro de boca 13 $\mathrm{cm}$., altura $25 \mathrm{~cm}$.). Lo más destacable de ella es su decoración pintada, típica de la iconografía del estilo Elche-Archena: un ave en su zona central (tipo E.I de ROS SALA, 1989, 40, fig. 15), enmarcada por filetes y bandas, apareciendo por debajo y entre la «diosa alada» una línea de strigilis o eses 


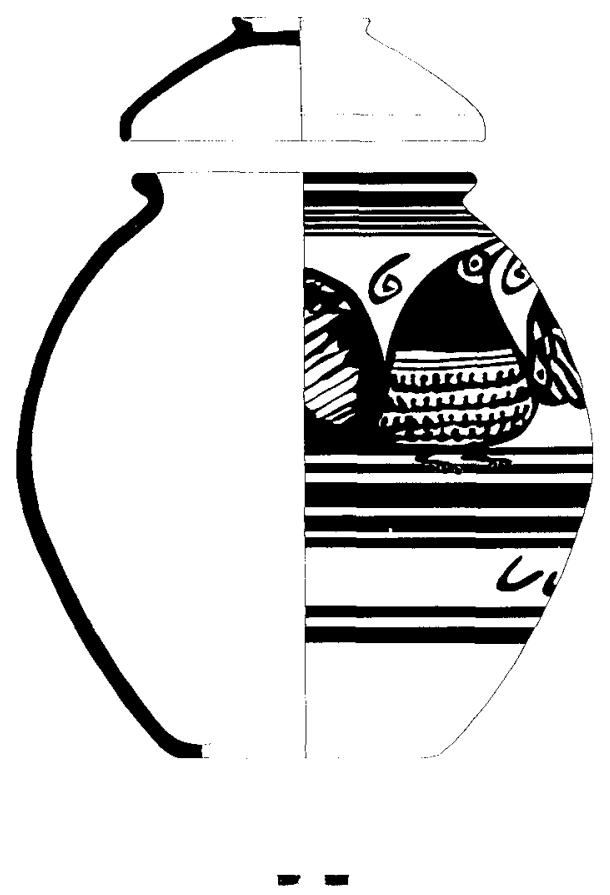

Fig. 3.- Tumba 2.

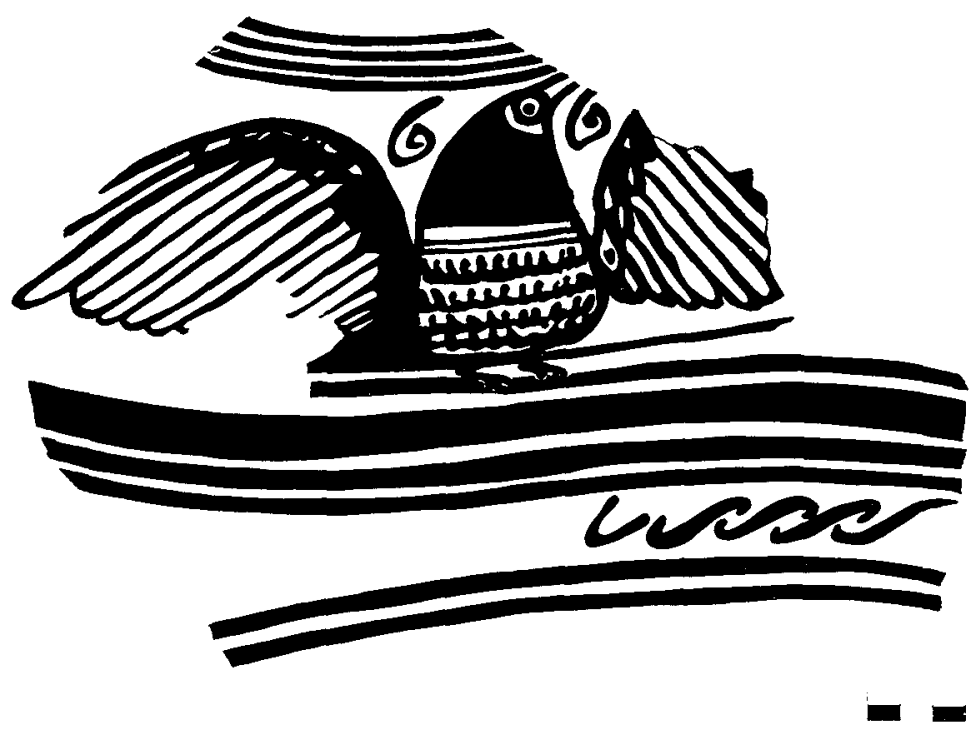

imbricadas con inclinación hacia la derecha (tipo A. 10.2. de ROS SALA, 1989, 37, fig. 11).

Tipológicamente, puede relacionarse con la urna de la tumba 3, aunque en la parte de la vasija que conservamos no aparecen las asas. Se trataría, en este caso, de una urna del tipo XVIb de ROS SALA (1989, 121, fig. 47).

$\mathrm{Su}$ identificación como urna cineraria no es segura, pero su aparición (siempre según los descubridores) cubierta por un cuenco-tapadera de cerámica común y borde vertical (diámetro boca $15 \mathrm{~cm}$.), tipo X de ROS SALA (1989, 104, fig. 39), nos hacen pensar en esta posibilidad. Parece que esta urna iba acompañada de otra olla más grande, cuya característica más importante era la de presentar una decoración pintada de círculos concéntricos y líneas. No obstante, al encontrarse en paradero desconocido, no la hemos podido estudiar.

- SIGILLATA: aparece un pequeño plato muy fragmentado con moldura exterior en la unión de la pared y la base (DRAG. 18, RITT, 2-Ab).

\section{Tumba 3}

En una situación intermedia entre la tumba 2 y la 4, apareció un túmulo de piedras que cubría una urna cineraria con tapadera y a su ajuar. Dicha urna estaba rodeada también de piedras, y se encontraba depositada en un agujero practicado en la roca madre.

Materiales:

- URNA FUNERARIA: recipiente de boca estrecha (diámetro boca $10 \mathrm{~cm}$., altura $26 \mathrm{~cm}$.), pero sin cuello, cuerpo globular, dos asas verticales enfrentadas que parten por debajo del borde, y base rehundida.

Morfológicamente, responde al tipo III de la necrópolis de Bari (ALMAGRO GORBEA, 1984, 203, fig. 113), aunque con las asas más desarrolladas y colocadas, como ya se ha indicado anteriormente, en la parte superior de la pieza, y no en la zona medial como ocurre en Baria. Almagro establece una fecha para las mismas, según el ajuar, en principios del siglo I d. C. De una manera más clara, puede relacionarse con alguna de las urnas aparecidas en la necrópolis de la Torre Ciega, en Cartagena (GONZÁLEZ SIMANCAS, 1921, 21-22, lam. II-III; idem., 1929, lam. III; BELTRÁN, 1947, fig. 1), enmarcables dentro del pithiskoi, forma XVI b de ROS SALA (1989, 121, fig. 47).

Los ejemplares de Torre Ciega iban acompañados de un ajuar (sigillatas orientales, tipo Ken- 

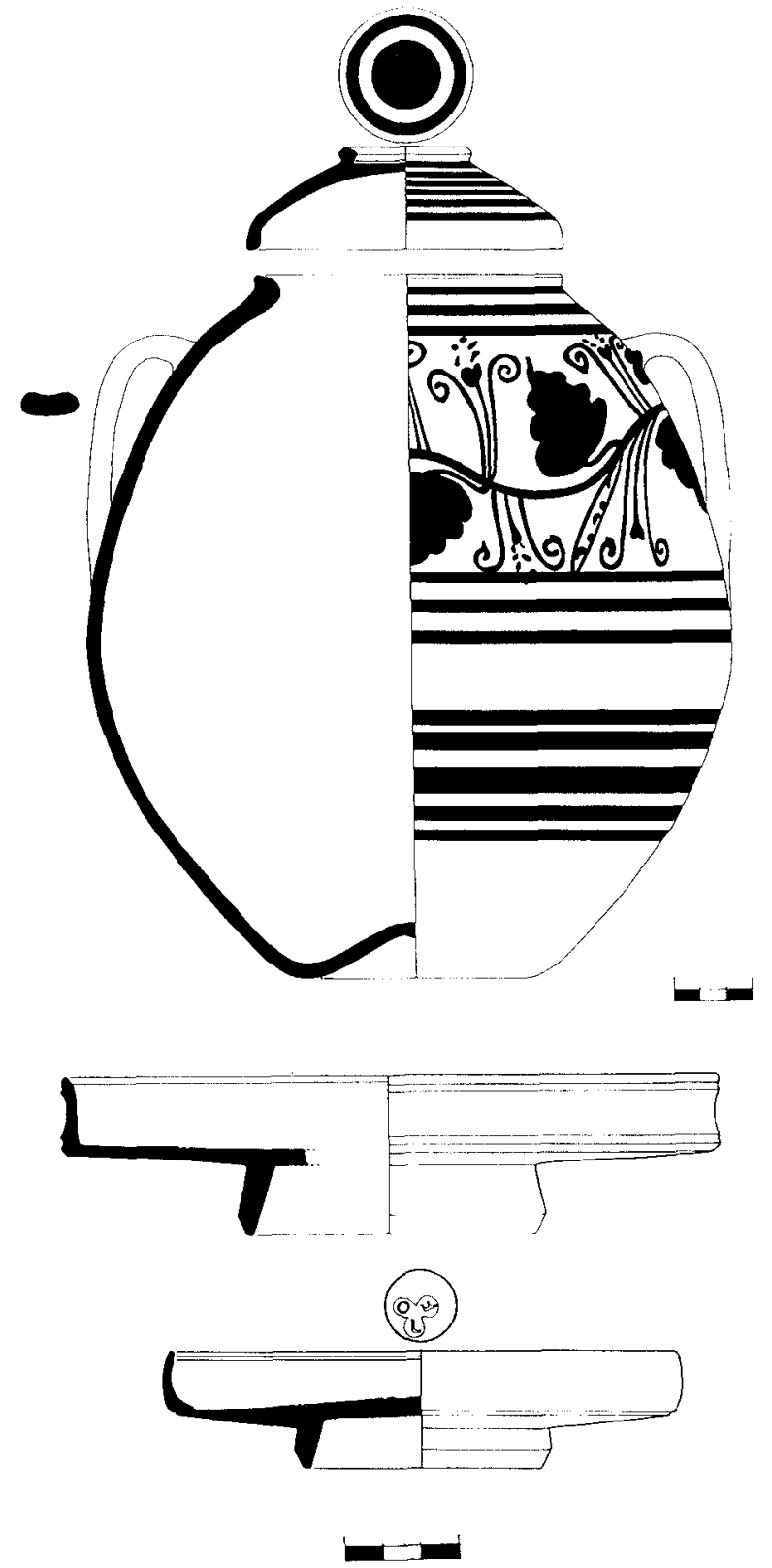

Fig. 4.- Tumba 3.

yon 15 y T.S.:A. Halt. 7) que nos permite fechar la fabricación de estas urnas en la primera mitad del siglo I d. C.

Su aparición exclusiva como urnas de incineración, hacen pensar en una posible fabricación con dicho fin.

La vasija que ahora estudiamos presenta una decoración con pinturas fitomorfas, formando un friso horizontal bajo el cuello, que es delimitado, tanto por arriba como por abajo, por filetes. La decoración vegetal, a modo de metopas, la componen, por un lado, una bella composición formada por una guirnalda de hojas de yedra con sus nerviaciones (tipo B.3.2 de ROS SALA, 1989, fig. 14), semejante a la existente en la urna citada de la necrópolis cartaginesa, y a la que decora una pátera con pie fracturado encontrada en el Tossal de Manises (LLOBREGAT, 1972, fig. 110); también es muy frecuente en el nivel D íbero-romano de La Alcudia de Elche. En el otro panel central, aparecerán hojas estrechas y alargadas unidas también por nerviaciones. Entre ambas, varios filetes verticales.

Con lo dicho, esta urna debe enmarcarse en un momento inicial del cambio de era, que no puede sobrepasar la mitad del siglo I d. C.

El cuenco-tapadera que cierra la urna es de características formales similares al de la tumba 2 (tipo X de ROS SALA, 1989, 104, fig. 39; tipo «reentrante» de NORDSTRÖM, 1973, II, 110), aunque aquí aparece decorado exteriormente de líneas pintadas sobre su superficie, así como de círculos concéntricos en la parte externa de la base. Según Ros Sala, sus dimensiones (diámetro boca $11 \mathrm{~cm}$.), así como el que la unión entre galbo y labio siempre aparece con un acentuado punto de inflexión, parecen responder a imitaciones de páteras campanienses (forma 5/7 Campaniense B, forma 21 de Lamboglia, etc.). Por tanto, se podrían fechar entre fines del s. II o I a. C.

La semejanza de urna y cuenco-tapadera que se observa entre las tumbas 2 y 3 parece clara, y hay que reseñarlo en la medida que puede estar reflejándonos un comportamiento prefijado en el ritual funerario de ésta u otras necrópolis.

- SIGILLATA: son dos los recipientes cerámicos de estas características aparecidos en esta tumba.

El primero, es una pátera (DRAG. 17B) que presenta sus paredes verticales con apliques, y el borde, aunque primeramente es reentrante, termina ligeramente exvasado. En la parte alta y baja de las paredes aparecen sendos filetes horizontales que surcan toda la pieza. Pie en alto en anillo. En el fondo interno aparece una decoración de incisiones concéntricas.

Esta forma aparece en época de Augusto y pervive hasta la época flavia, sobre todo en TiberioClaudio. 
Paralelos de esta pieza, dentro de contextos funerarios, los tenemos documentados en la incineración n. ${ }^{\circ} 28$ de la necrópolis de Ballesta (Ampurias), que se fecha en los últimos años de Augusto y primeros de Tiberio (MARTÍN ALMAGRO, 1955, 64); así como en las tumbas 14 y 32 de la necrópolis italiana de Nave (PASSI, 1987, 58 y 81), de época Julio-Claudia (15 d. C.-54 d. C.).

El segundo recipiente es un plato (RITT.1) con paredes rectas, ligeramente encurvadas, escaso borde con acanaladuras internas. Pie alto de anillo. En el fondo interno aparece una doble banda de incisiones concéntricas, así como un sello trifólico en el centro (característico de la segunda década del siglo I d. C.) con las siglas L.F.O.: L. F(ASTIDIENUS) O(PTATUS).

Paralelos de éste los encontramos, con la misma forma abreviada y composición, en Luna (Florencia), según recogen OXÉ-COMFORT $\left(1968\right.$, n. $^{\circ}$ 664 y $674 \mathrm{a}$ ) existiendo, con otras variaciones en Fiesole, Solunto, Génova, Nimes, Alexandría, Tarragona (CIL II, 4970, 251), Valencia (idem, 4971, 5a y 5b), Cartagena (idem, 6257, 77), Sevilla, etc.

- OTROS OBJETOS: huesos decorados a base de incisiones que forman motivos geométricos, florales, etc. Su forma es muy variada, apareciendo, sobre todo: tubos, placas y anillos. Vienen interpretándose en la bibliografía científica, como partes de instrumentos musicales (¿flautas?), revestimientos de cajas o pequeñas arquetas de madera, estuche de alfileres, etc.

Es difícil, teniendo en cuenta las circunstancias que rodean a este estudio, poder distinguir pormenorizadamente grupos diferenciados de huesos decorados en cada una de las tumbas existentes, no obstante sí sabemos que aparecieron tanto en el ajuar de la tumba tres, como en la de la tumba 5 .

Se trata de un conjunto muy interesante de huesos decorados, en donde fundamentalmente aparecen incisos los siguientes motivos: palmetas, ovas, radios concéntricos, entramados de rombos y sucesiones de anillos. Alguno de estos ejemplares creemos pueden relacionarse con posibles flautas y botones, aunque la mayoría deben corresponder a la decoración externa de arquetas de madera a base de placas. El significado funerario de éstas se nos escapa, aunque pudieron contener objetos personales del difunto, e incluso en el caso de las incineraciones directas, las cenizas de aquél.

Este tipo de manifestación decorativa en hueso, está atestiguado en otras necrópolis alto- imperiales, como las de Ampurias (ALMAGRO, 1955: Inc. Robert, 5, 94; Inc. Torres 16, 159-60, fig. 128; Inc. Torres 48, 178, fig. 152; Inc. Torres 59, 190, fig. 162; Inc. Nofre 27, 211 ; Inc. Patel 21, 248, fig. 220; Inc. Bonjoan VI, 269, fig. 239; Inc. Anfiteatro 1, 255, fig. 230), Nave (PASSI, 1987: tumba 6, 129), Cividate (ABELLI CODINA, 1986: tumba 9D, 47, Tav. XXI, fig. 1), Blicquy (DE LAET y VAN DOORSELAER y SPITAELS y THOEN, 1972: tumba 52, 89, pl. 20).

\section{Tumba 4}

Apareció sobre la roca madre, y la formaban un kálathos de amplias dimensioines decorado con pintura de tradición ibérica, que contenía las cenizas del difunto. Dicha urna estaba tapada por una gran pátera de sigillata. Su posición no era vertical, sino que la urna apareció tumbada cn una piedra que, apoyada sobre la pátera, impedía su caída.

\section{Materiales:}

- URNA CINERARIA: se trata de un kálathos de paredes más o menos rectas (forma trococónico-invertida) acabadas en un borde recto y exvasado, sin estrangulamiento (tipo I b de ROS SALA, 1989, 74, fig. 29). La base, como en el resto de urnas funerarias de esta necrópolis, aparece rehundida, y presenta dos asas de cinta horizontales que, enfrentadas, se sitúan por debajo del borde.

Claramente estamos ante un derivado de kálatos ibérico que, sin asemejarse totalmente (sobre todo en lo que a la base se refiere) al tipo III de Ampurias (ALMAGRO, 1955, 139. Inc. n. ${ }^{\circ} 16,30 \mathrm{y}$ 51) presenta rasgos comunes como: su perfil en «U», su amplia boca y su origen común en la forma ibérica comentada. En aquella necrópolis, la incineración $n .^{\circ} 51$, que es la que presenta una urna más parecida a la que ahora nos ocupa, se fecha por el ajuar en época de Tiberio. Se trata de una forma de kálathos no anterior al s. II a. C., siendo muy frecuentes durante todo este siglo, así como en el s. I a. C., pudiendo perdurar hasta mediados del s. I d. C. (aunque reduciendo su tamaño y presentando una decoración muy degradada).

La vasija se haya profusamente decorada con motivos pintados muy simplificados. Entre dos bandas pintadas a modo de triglifos (varias líneas verticales) y metopas en cuyo interior sólo aparece una línea vertical con un círculo negro en su parte media (tipo A. 1.6 de ROS SALA, 1989, 29, fig. 7), 

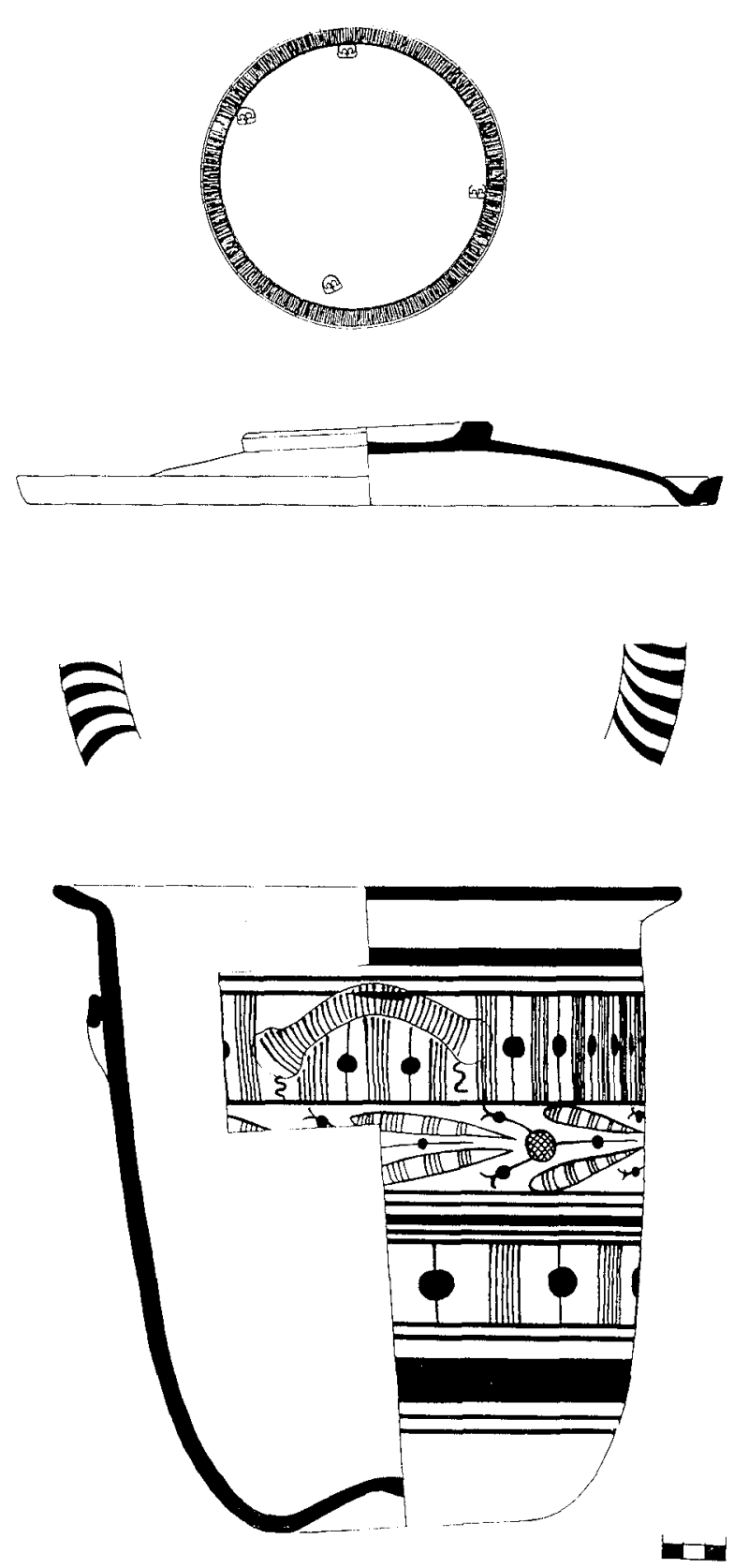

Fig. 5a.- Tumba 4.

se encuentra el panel central. Éste presenta una decoración de «peces estilizados deformes», (ABASCAL PALAZÓN, 1986) en grupos de dos, separados por un ángulo de extremos rematados con un motivo vegetal esquematizado (¿un capullo de una flor con dos peristilos?). Para ROS SALA (1989, 40, fig. 14, variante del tipo B.3.4), se trataría de
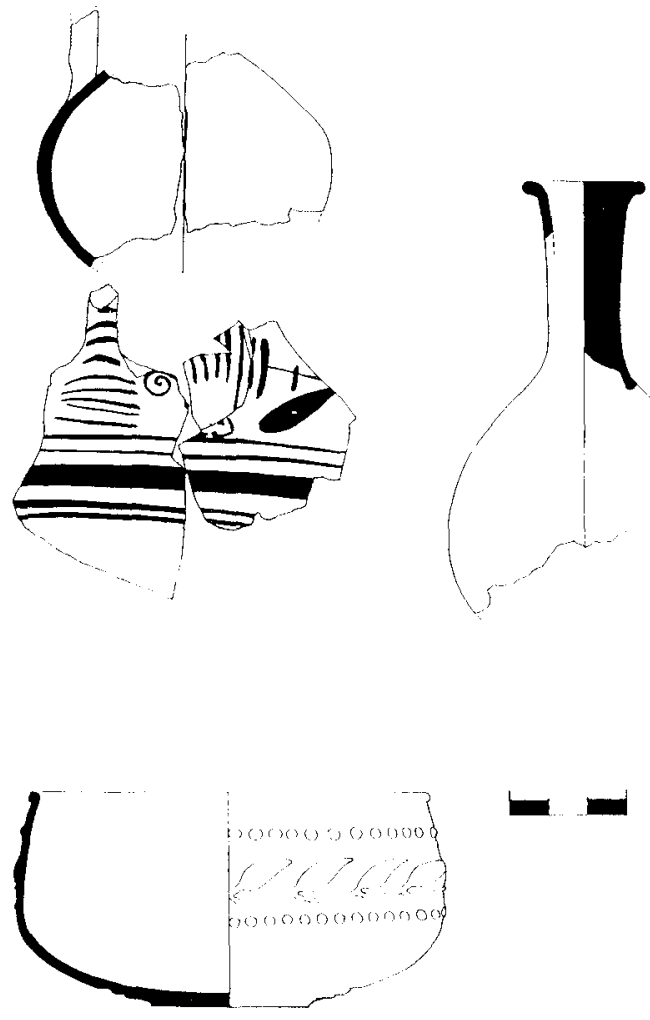

Fig. 5b.- Tumba 4.

hojas esquematizadas. Tanto las asas de cinta como el borde aparecen decorados con líneas.

Cerrando esta urna, apareció una gran pátera de sigillata con pie en anillo, paredes curvas y borde vuelto al exterior. En su interior, aparece una decoración incisa en ruedecilla de tipo radial, con cuatro estampillas de ancla enfrentadas dos a dos. Su acabado no es del todo perfecto, ya que presenta una cierta disimetría en el borde. El barniz, de no muy buena calidad, es de color marrón claro.

$\mathrm{Su}$ forma, que recuerda a las producciones en cerámica campaniense, las estampillas, la decoración radial sobre el fondo, la mala calidad del barniz y el mal acabado de la pieza nos hacen pensar en una producción local de imitación de las primeras sigillatas aretinas.

- PAREDES FINAS: apareció, formando parte del ajuar, un vasito de este tipo con paredes curvas, entrantes en su parte superior, el labio es redondeado y el pie indicado (MAYET XXVIII). Presenta decoración a la barbotina sobre la parte superior de la panza, a base de hojas de agua (VEGAS 35; RICCI 211). 
Son varios los paralelos conocidos de este vaso: tumba XII de Baelo (REMESAL 1979, fig. 15, 15), necrópolis de Carmona (BENDALA, 1976, lam. XLIV, 11. 109), y Alcudia de Elche (MAYET, 1975, n. ${ }^{\circ} 458$ ).

Cronológicamente, se sitúa entre la época de Tiberio (14-37 d. C.) y la segunda mitad del siglo I d. C., pudiendo estar su centro de producción en la Bética (COMFORT, 1939).

- OTROS: fragmento de un pequeño olpe con pintura de tradición ibérica. Se conserva parte de la panza, así como el apoyo del asa que arrancaría del cuello del recipiente. La decoración pintada conservada es, precisamente la de la zona central, siempre con más cantidad de motivos dibujados, y está enmarcada por su parte inferior por varios filetes horizontales de distinto grosor. Se aprecia un motivo frecuente en las urnas de incineración de tradición ibérica encontradas en las necrópolis altoimperiales, ya aparecido en alguna de las urnas de nuestra necrópolis, esto es, peces estilizados deformes, en grupo de dos, separados por un ángulo de extremos rematados en espiral cortado por trazos paralelos. Así, podemos verlo en la necrópolis de la Torre Ciega, Cartagena (GONZÁLEZ SIMANCAS, 1929; BELTRÁN, 1947); siendo también un motivo conocido en la Alcudia (RAMOS FOLQUÉS, 1962; RAMOS FOLQUÉS, 1970; RAMOS FOLQUÉS y RAMOS FERNÁNDEZ, 1983). El fragmento de asa, por su parte, presenta una decoración de líneas horizontales paralelas.

- UNGÜENTARIOS: aparece un recipiente de esta clase, de características semejantes al encontrado en la tumba 1 , aunque con el cuello más corto.

\section{Tumba 5}

Apareció al lado opuesto de la estancia industrial donde fue encontrada la tumba 2.

Materiales:

- PAREDES FINAS: son dos los ejemplares encontrados. El primero se trata de una copita hemiesférica de cuerpo carenado, y dos asas aplicadas sobre la sección vertical de la panza, por encima de la carena (MAYET XXXVIII; VEGAS 34, 10 ), pero sin presentar ningún tipo de decoración.

El segundo recipiente, es un cubilete sin base, de paredes verticales, y panza hemiesférica decorada con una ranura que atraviesa horizontalmente toda la pieza (MAYET XXXIII). Suele aparecer en
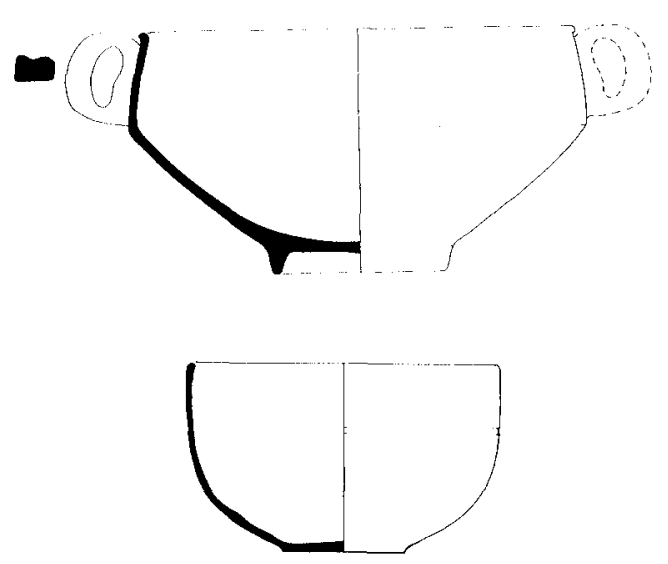

Fig. 6.- Tumba 5.

los niveles fechados en época de Augusto o Tiberio, presentando abundantes paralelos: Incineración Torres n. ${ }^{\circ} 40$ de Ampurias (ALMAGRO, 1955, 172, fig. 144), sepultura 34 de Pollentia (ALMAGRO y AMORÓS, 1953-54, 269, fíg. 32.5), etc.

- OTROS: a parte de los objetos hasta ahora comentados, en la tumba 5 aparecieron, al igual que en la tumba 3, huesos decorados de las mismas características que aquéllos. Interesa, del mismo modo, destacar la aparición de una moneda de Augusto que nosotros no hemos podido ver, pero que fecharía la tumba en un momento de transición de la época de Augusto a Tiberio.

\section{Tumba 6}

Situada en una hondonada de la roca, aparecían cenizas y huesos calcinados, sin urna.

Materiales:

- OLPE: este tipo de recipiente está ampliamente difundido en las necrópolis romanas. Algunos han querido ver en ellos uno de los elementos típicos de los contextos funerarios (SENA CHIESA, 1979). Su función doméstica, por otro lado, es bien conocida, como contenedores de líquidos.

No obstante, por ahora no existe un estudio detallado que determine los tipos y la cronología de los olpes. Por otro lado, al tratarse normalmente de producciones locales, $y$ al existir una variada tipología que se prolonga durante mucho tiempo, hace más difícil su estudio. Pese a lo dicho, existen algunos trabajos que pueden ayudarnos (SIMONETT- 

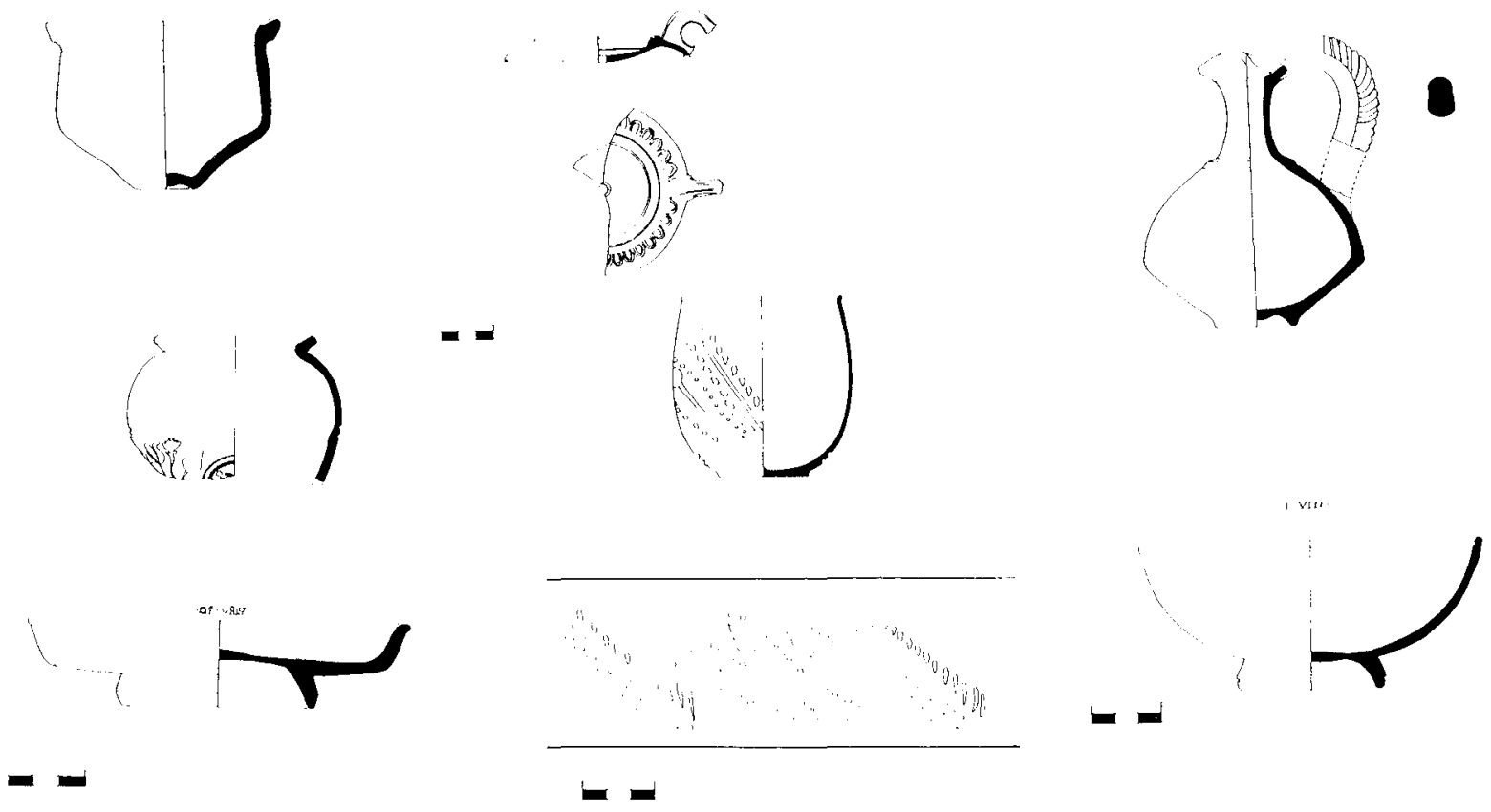

Fig. 7.- Tumba 6.

LAMBOGLIA, 1967-71; DONATI, 1979; GRAUE, 1974; MARABINI, 1973).

Los olpes, tipológicamente, se han dividido en distintos tipos:

- de cuerpo piriforme

- de espalda carenada

- de espalda acentuada

- de borde triobulado

- con collarino

- de pequeñas dimensiones

- recipiente con dos asas

- de ancha boca

Entre los materiales aquí estudiados sólo aparece un ejemplar de este tipo de recipientes, aunque de gran interés. Se trata de un olpe con pico trilobulado, borde exvasado, cuello corto y arqueado que termina en un reborde; cuerpo ovoide al principio con carena en la zona media de la pieza, adoptando una forma piriforme a partir de ella, pie en anillo y fondo plano. El asa, entrelazada parcialmente en su parte exterior, nace del borde de la pieza, para terminar en la espalda, pero por encima de la carena. La pasta es grisácea con algunas partículas de desgrasante blanco que incluso llegan a sobrepasar el engobe exterior de la pieza, que es de color gris brillante/metálico.
Su adscripción a un tipo concreto de los planteados líneas atrás parece difícil, toda vez que las características que los definen pueden interrelacionarse entre sí, dando lugar a nuevas formas. Pese a ello, creemos que se acerca al contexto de los olpes de pequeñas dimensiones, no sólo por su tamaño, sino sobre todo, por su factura claramente más cuidada que en los otros tipos (algunas piezas presentan barnices sobre su superficie). La forma de estos olpes suele caracterizarse por tener un cuello estrecho y más o menos largo, pero el cuerpo es muy variable (carenado, redondeado, piriforme, etc.). Desde el punto de vista cronológico, es uno de los objetos más determinantes, adscribiéndose a época tardo-republicana y augustea, con posibilidades de prolongarse sólo hasta época proto-tiberiana (L. PASSI, 1987, 188).

Por su parte, los olpes con espalda carenada, muy numerosos en contextos tumbales (MACCHIORO, 1984, 15), pertenecen a época augustea, con pocas posibilidades de prolongar su producción (SIMONETT-LAMBOGLIA, 1967-1971, 226, 229; FORTUNATI ZUCCÁLA, 1979, 11; NOBILE, 1984, 90-92; ROVELLI, 1985, 433), por lo que viene a coincidir, al igual que el anterior tipo con la cronología de la necrópolis que ahora estamos tratando. 

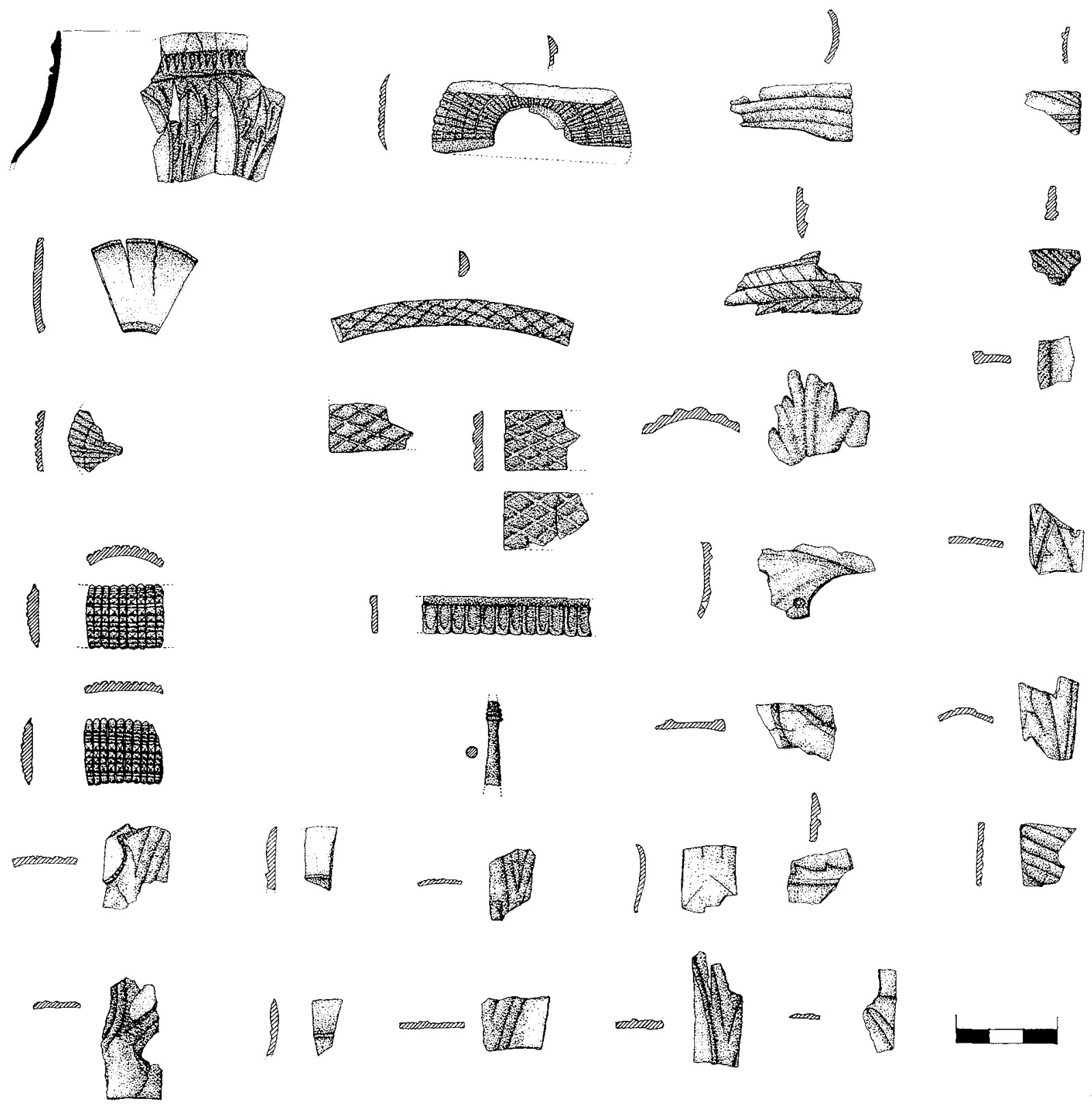

Fig. 8.- Huesos decorados de las tumbas 3 y 5 .

Por último, los olpes con borde trilobulado, aunque relacionados con otras formas, sí presentan una amplia cronología que va desde inicios del siglo I d. C. (SIMONETT-LAMBOGLIA, 1967-1971, 229), hasta época flavia (ROVELLI, 1985, tav. 87, 15).

Dentro de la tipología de M. Vegas, estaríamos ante el tipo 46 (VEGAS, 1973, 109, fig. 39), formado por jarras con pico triobulado, cuello corto y muy arqueado, cuyo cuerpo es panzudo al principio para luego convertirse en piriforme. Para esta autora su origen están én los oinochoes griegos. EI barro de este tipo de jarras es muy homogéneo: gris claro con puntitos negros, quedando su superficie oscura y paredes rugosas. Vegas nos presenta en su libro varios ejemplos, de los que sólo los números 2 (Pollentia, CNO, $\mathrm{B}_{1}-\mathrm{B}_{2}, 68$. Casa NW. Presenta una coloración exterior gris metálico, y está fecha- 


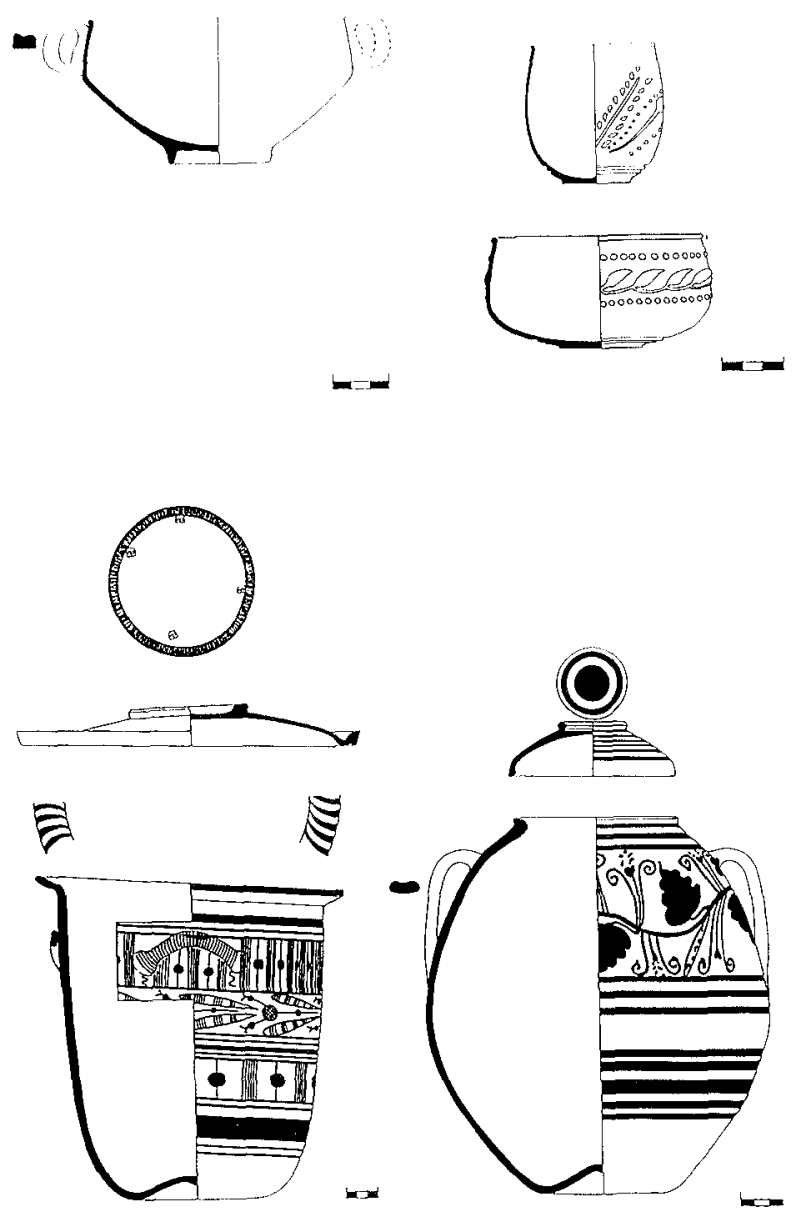

Fig. 9.- Conjunto de los materiales.

do entrela $2 .^{a} 1 / 2$ del s. I, y comienzos del s. II d. C.), y 4 (Ostial II, lam. 57, 824. Cuerpo carenado, barro gris con impurezas, y fechado en el s. I d. C.) podrían relacionarse de alguna manera con la pieza que nos ocupa.

En la necrópolis romana della Mandana di Intimiano (BIANCHI, LURASCHI, VASSALLE, 1983, 208, tav. f) apareció en la tumba 6 un olpe con amplia espalda convexa, vientre con perfil troncocónico y carena bien marcada, similar al que nos ocupa salvo en la boca que no es trilobulada y en el asa que en aquélla es lisa. Esta pieza es fechada al principio del siglo I d. C. por sus descubridores, en contraposición a la cronología dada por Lamboglia para una pieza parecida en la necrópolis de Muralto, que data entre los años 40-60 d. C. (SIMONETT-LAMBOGLIA, 1967-1971, Muralto, tumba 8, n. ${ }^{\circ} 7$, p. 230 ).
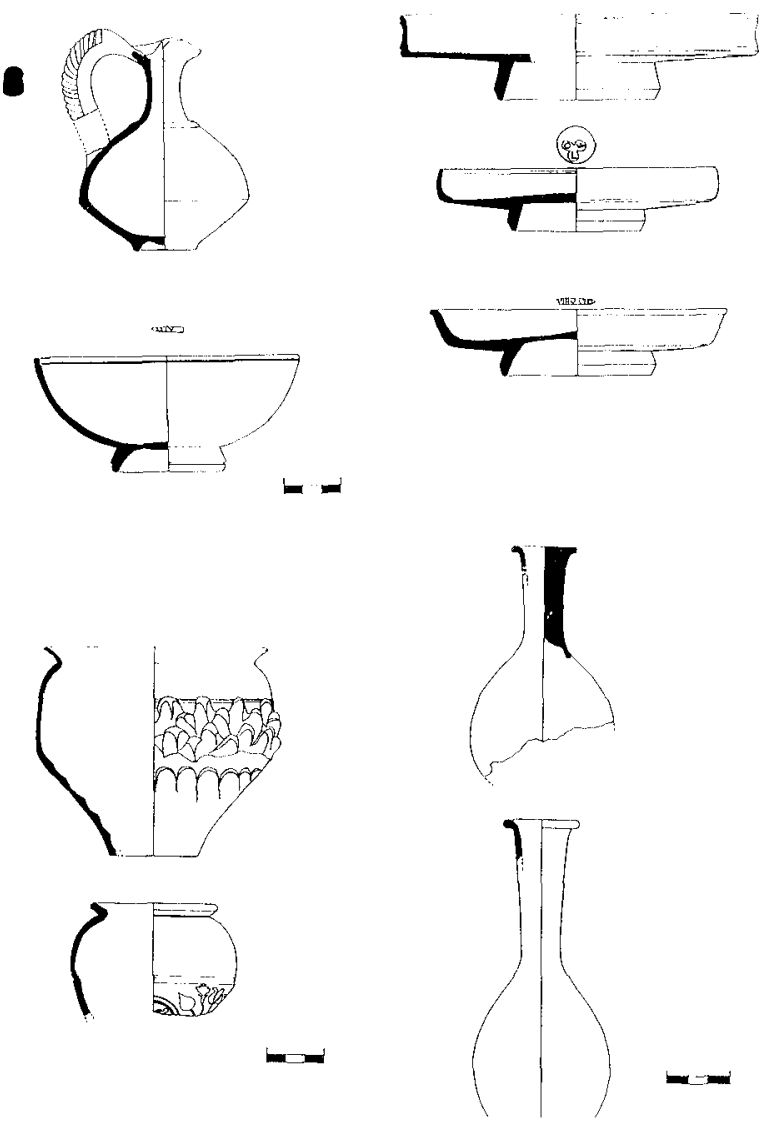

En Settefinestre aparece un olpe trilobulado (A. RICCI, 1988, tav. 34.8, 125), pero con engobe externo de color rosáceo, cuello muy corto y asa lisa, que apareció en el período II A2 (fase Adriana) y IV (etapa tardo-antigua). Otros paralelos se encuentran en Ostia (ZEVIPOHL, 1970, fig. 55, n. ${ }^{\circ} 388$, OSTIA III, 281, tav. LXX, fig. 639; OSTIA II, 8788 , tav. XIX, 320 a $337_{\mathrm{a} \cdot \mathrm{b}}$; OSTIA I, 90-91, tav. $\mathrm{XIV}, \mathrm{n} .{ }^{\circ} 297$ a 300 ) datados desde principios del s. I a inicios del II d. C.; en Ventimiglia (LUNI II, 510, tav. 266, fig. 1) datado entre los siglos II al V d. C.; en Vindonissa (ETTINGER-SIMONETT, 1952, 80 , tav. 21,472 ), etc.

De todos ellos, quizá con los que más pueda relacionarse sea con los citados tanto en OSTIA II, como en VENTIMIGLIA, ya que presentan todos ellos un color gris tanto en la pasta como al exterior. Por el momento es difícil poder hablar de ma- 


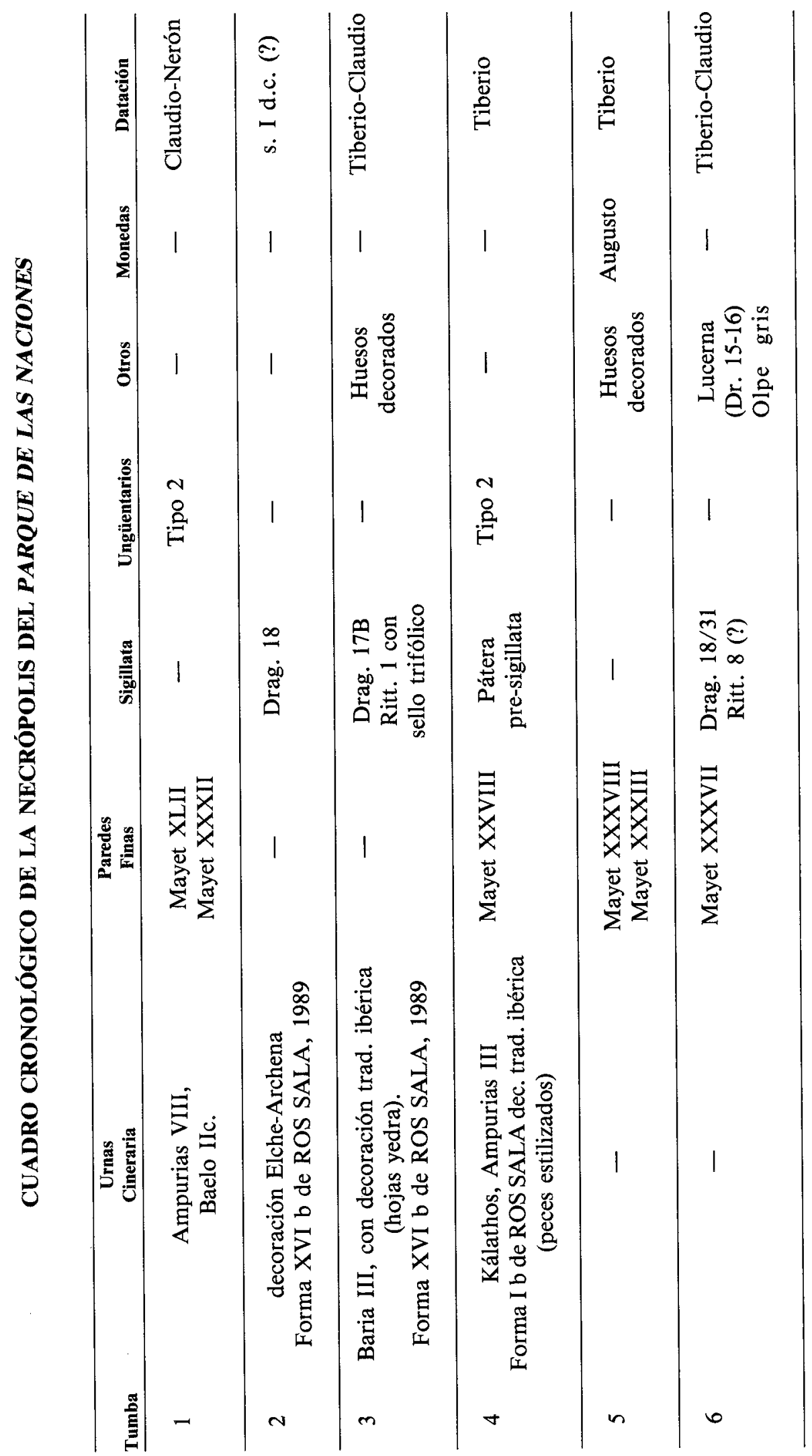


pas de distribución de estas piezas, pero gracias a la excavación de Ventimiglia podemos decir que empiezan a aparecer en la costa septentrional del $\mathrm{Me}$ diterráneo occidental en torno al primer decenio del s. I d. C. (como se confirma en Ostia y ahora en Alicante, lo que hace pensar que los olpes trilobulados debió ser la forma más peculiar de la producción en cerámica gris de ese siglo), continuando su aparición hasta el primer decenio del s. II d. C. (Ostia).

- SIGILLATAS: son varios los recipientes de terra sigillata aparecidos en esta tumba. Así, nos encontramos con un plato de paredes exvasadas, ligeramente convexas, unidas al fondo del plato con una carena poco acentuada y redondeada. El borde es ligeramente exvasado y el pie de anillo muy alto (forma DRAG. 18/31). Presenta un sello ilegible sobre el fondo interno de la vasija.

Un recipiente similar aparece en las tumbas 5 , 8,10 y 14 de la necrópolis italiana de Nave, fechadas por el resto de su ajuar en época de Tiberio; así como en las tumbas $18,22,25,29$ y 32 de la misma necrópolis, fechadas en época de Claudio (L. PASSI, 1987).

También existe una copa de la forma RIT.8, así como un interesante fragmento de vaso fabricado en barro marrón, cuyo barniz presenta una tonalidad amarillenta (¿fallo de cocción?). Presenta un borde vuelto, cuerpo globular, que se muestra liso en la zona de los hombros, mientras que en la mitad inferior aparece ricamente decorado con motivos vegetales y alguna figura dentro de un círculo. Corresponde, en TSH, a la forma MEZQUIRIZ2 (pero decorada), y se inspira en el cuenco galo DECHELETTE 67. Cronológicamente surje en época flavia, apareciendo hasta el siglo II d. C.

Paralelos de esta forma decorada encontramos en la necrópolis de Carmona (M. BENDALA, 1976, R.E. 357, 108, lam. XLIV.1) fechada en el período Nerón-Vespasiano (FERNÁNDEZ-CHICARRO, C., 1970, 55); en el Taller de Andújar fechada en la 2 . $^{a} 1 / 2$ del s. I y principios del II d. C. (MAYET, 1984, Pl. XXVII.70, 47; ROCA ROUMENS, M., 1976, Pl. 21, . ${ }^{\circ} 69$ ); y también en el Taller de Tritium Magallum, en Tricio, Logroño (MAYET, 1984, Pl. LXXX 270 a 281, 79; Pl. CXXII. 524, 85).

- PAREDES FINAS: son varios los ejemplares que de este tipo aparecen formando parte del ajuar de la tumba. Nosotros sólo hemos podido estudiar uno de ellos.
* MAYET XXXVII B: bol hemiesférico de pasta amarilla-avellana y barniz marrón-rojizo. Presenta una decoración a barbotina formada de palmetas oblicuas, perlas y hojas de agua, también oblicuas. Esta forma es fechada por Mayet de la época de Claudio hasta finales de la dinastía Flavia (MAYET, 1975), mientras que la decoración de palmetas pertenece a la segunda mitad del s. I d. C. (VEGAS, 1973, 87, fig. 28).

Paralelos aparecen en la necrópolis de Carmona (MAYET, 1975, fig. LIII. 440), y en la incineración n. ${ }^{\circ} 34758$ de la necrópolis de Belo (MAYET, 1975, fig. LIII. 441).

- LUCERNAS: tres son las que aparecieron, según siempre referencias orales. La primera, de ancho diámetro y con asa agujereada, se conserva fragmentada, presentando el disco liso, con el agujero de alimentación (infundibulum) en el centro; los hombros, decorados con ovas incisas, están separados del disco por un bocel estriado que forma una decoración de círculos concéntricos entre el disco y la orla. El engobe está entre el castaño oscuro y el marrón rojizo. Al no conservar la zona de la piquera, es bastante difícil adscribir la pieza a una forma tipológica clara; no obstante, la calidad de la factura, su ligero peso, la presencia de un fino barniz muy adherido y el contexto cronológico en donde ha aparecido (hecho que no podemos demostrar a ciencia cierta), nos hacen pensar que se trata de una lucerna de pico triangular con volutas (más propio sería denominarla de semi-volutas), característica de época augustea a flavia; aunque más concretamente sería adscribible a la época de Tiberio-Claudio, ya que es en ese momento cuando se produce una tendencia a la simplificación formal y decorativa (C. PAVOLINI, 1981, 148).

Tipológicamente, nos inclinamos a pensar en una forma CARTAGO IVD. VINDONISSA II, PONSHICH IIA1, PALOL 10.

Un paralelo muy similar al aquí estudiado, aunque sin asas, lo encontramos en la necrópolis romana de Mahón (RITA LARRUCEA, 1982, 45, n. ${ }^{\circ}$ 7, lam. XXVIII).

Las otras dos lucernas no han podido ser estudiadas por nosotros.

- CERÁMICA NO CLASIFICADA: fïg. Vasito que podría estar, dentro de la tipología de paredes finas, entre la forma MAYET XLII y la MAYET XLIII. Se trata de una pieza no muy frecuente, que presenta una coloración grisácea y paredes 
sin ningún tipo de decoración. Borde inclinado hacia afuera, paredes más o menos verticales y base piriforme con un pequeño ónfalo.

- VIDRIO: cuatro ungüentarios, dos de ellos aplastados y muy fragmentados.

- JOYAS: se encontró un camafeo de color granate y un fragmento de pasta vítrea.

- OTROS: apareció un pequeño objeto de arcilla con lo que parece ser un sello, en el que posiblemente esté representado un pez (¿delfín?).

\section{CONCLUSIONES}

Tras el estudio pormenorizado del material aquí expuesto, podemos decir que nos encontramos ante una necrópolis en donde no se aprecia una ocupación prolongada en el tiempo.

Si bien puede haber dudas sobre la composición de alguna de las 7 tumbas (por ejemplo la $n .^{\circ}$ 6 presenta conjuntamente materiales antiguos, como el olpe carenado, con otros de finales del siglo I d. C. o, incluso de principios del siglo II), circunstancia que hay que achacar a las características del hallazgo de los materiales en cuestión, parece claro que estamos ante una necrópolis con un arco cronológico que se extiende fundamentalmente desde la época de Augusto (la aparición de un ungüentario fusiforme de gran tamaño, no recogido en este estudio, así como la moneda augustea de la tumba 5, apoyarían esta fecha), hasta la época de TiberioClaudio.

En la necrópolis de Torre Ciega (Cartagena), y dentro de una urna cineraria de tradición ibérica semejante a las aquí estudiadas, apareció una moneda republicana de Sagunto (BELTRÁN, 1947, 159), circunstancia que refuerza, aún más si cabe, una cronología temprana para esta necrópolis, dentro del mundo alto-imperial.

Como ha estudiado ABASCAL PALAZÓN (1986, 29 ss.; 230 ss.), en la región levantina y murciana hay un amplio espectro de producción de cerámica pintada que marcan el tránsito desde lo puramente indígena a las producciones típicamente romanas, encontrándose el nexo entre ambos en la época de Augusto. Con posterioridad a esta fecha sólo se sigue produciendo en el taller cerámico de Elche que, según Abascal, difundirá a comienzos del s. I a. C. la olla globular documentada tanto en la necrópolis del Parque de las Naciones, como en la de la Torre Ciega y La Alcudia de Elche (nivel «C» $o$ alto-imperial).

Es este tipo de cerámica pintada pieza clave en nuestra necrópolis, ya que no sólo aparece muy bien representada entre las urnas cinerarias, sino que la encontramos en otro tipo de recipientes cerámicos (por ejemplo, el olpe de la tumba 6, así como otras piezas exhumadas en las excavaciones que el COPHIAM realiza actualmente en la zona de la necrópolis).

No entrarermos aquí en la enumeración de cada una de las piezas aparecidas en el contexto alicantino-murciano de época alto-imperial (La Alcudia, Torre Ciega, Santa Pola, Tossal de Manises, Denia), ya que Abascal y Ros Sala han realizado, respectivamente, un excelente trabajo sobre el particular. No obstante, sí incidiremos en la importancia que esta nueva aportación de las necrópolis del Parque de las Naciones y del Fapegal tienen para el mejor estudio de esta manifestación artística de clara tradición ibérica, así como para su contextualización en las necrópolis alto-imperiales.

La posible existencia, en una misma tumba de esta necrópolis alto-imperial (la $\mathrm{n} .{ }^{\circ} 2$ ), de una urna con decoración tipo Elche-Archena que contiene las cenizas del difunto, y de una olla del primer estilo decorativo ibérico acompañando a aquélla, plantea problemas de gran interés. No obstante, y debido a la particular situación en que aparecieron estos materiales, no podemos dar nada por seguro, debiendo esperar a la finalización de las excavaciones dela necrópolis del Parque de las Naciones y del $\mathbf{F a}$ pegal, y al posterior estudio de los materiales en ellas exhumados, para sacar conclusiones más firmes al respecto.

Por último, hay que resaltar la importante pervivencia del sustrato cultural indígena (ibérico en nuestro caso) en esta necrópolis romana, y dentro de un rito con tantas connotaciones socioculturales como es el religioso-funerario.

Ello vendría apoyado, no sólo por la aparición de urnas pintadas con decoración de tradición ibérica utilizadas como contenedoras de las cenizas de los muertos, sino a lo mejor también por la existencia, como hemos visto, de urnas con decoración característica del estilo Elche-Archena e incluso del primer estilo decorativo. En otra publicación se incide sobre este punto, por lo que no vamos a entrar más profundamente en el mismo (LLOBREGAT, M.; ROSSER, P., 1989). 


\section{BIBLIOGRAFIA}

ABASCAL PALAZÓN, J. M. La cerámica pintada romana de tradición indigena en la Península Ibérica. Centros de Producción, comercio y tipología. Madrid, 1986.

ABELLI CONDINA, F. II caso di Civitate: le necropoli, in $L a$ Valle Camonica in etá romana, Brescia, 1986, págs. 45-51.

ALMAGRO, M. y AMORÓS, L. Excavaciones en la necrópolis romana de Can Fanals de Pollentia (Alcudia, Mallorca). Rev. Ampurias, tom. XV-XVI, pág. 237-8. Barcelona.

ALMAGRO, M. Las Necrópolis en Ampurias. Vols. I y II. Barcelona. 1953 y 1955.

ALMAGRO GORBEA, J. M. La necrópolis de Baria (Almería). Campañas de 1975-78. $E A E, 129.1984$.

ARRIBAS, A.; TARRADELL, M.; WOODS, D. Pollentia I. Excavaciones de Sa Portella, Alcudia (Mallorca). EAE 75. 1973, Madrid.

- Pollentia II. EAE, 98. 1978, Madrid.

BELTRÁN MARTÍNEZ, A. Breves notas sobre la cerámica ibérica pintada del Museo de Cartagena. III $C A S E$, Murcia, 1947, págs. 159-163.

BENDALA GALÁN, M. La necrópolis romana de Carmona (Sevilla. Sevilla, 1976.

BIANCHI, E. Tomba romana di Cremato alla Mandona di Intimiano (Como), in Oblatio, Raccolta di studi onore di $A$. Calderini, Como, 1971, págs. 153-166.

BIANCHI, E.; VASSALLE, E.; LURASCHI, G. La Necrópoli romana della Mandana di Intimiano. Societá Archeologica Comense. Storia di Capiago Intimiano, III. Como, 1983.

CARANDINI, A. Ostia I. Le Terme del Nuotatore, scavo dell'ambiente IV, Studi e Miscellanei, 13.

- Ostia II. Le Terme del Nuotatore, scavo dell'ambiente I. Studi e Miscellanei 16. Roma, 1980.

- Ostia III. Le Terme del Nuotatore, scavo degli ambiente III, IV, VIl. Scavo dell'ambiente V e di un saggio nell'area SO. Studi e Miscellanei, 21.

COMFORT, H. Some roman barbotine bowls and theirs connections, en The Art Bulletin, XXI, 1939, págs. 272-279.

DE LAET, S. J.; VAN DOORSELAER, A.; SPITAELS, P.; THOEN, H. La Nécropole gallo-romaine de Blicquy (Hainaut-Belgique). Dissertationes Archaelogicae Gandenses. Vol. XIV. Brugge, 1972.

DEL AMO, M. Estudio preliminar sobre la romanización en el término de Medellín (Badajoz). La Necrópolis de E1 Pradillo y otras villas romanas. $N A H$, Arqueología 2, pág. 53. Madrid, 1973.

DENEAUVE, J. Lampes de Carthage. Ed. CNRS, París, 1974.

DONATI, P. Locarno: la necropoli romana di Solduno, Bellinzona, 1979.

DU COUDRAY, La BLANCHÉRE, P. GAUCKLER. Catalogue du Musée Alaoui, 1897 (Colecctions des musées de l'Algérie et de la Tunisie).

DUMOULIN, A. Les puits et les fosses de la Colline SaintJacques á Cavaillon (Vaucluse). Gallia, T. XXIII, fasc. 1, 1965 , págs. 1-85.

ENNABLI, A.; MAHJOUBI, A.; SALOMONSON, J. W. La Nécropole romaine de Raggada. Institu National d'Archeologie et d'Art. C. R. A. H. Colecc. Notes et Documents, VIII. Ministere des Affaires Culturelles et de l'Information, Túnez, 1970 y 1973.

ETTLINGER, E.; SIMONETT, C. Römische Keramik aus dem Schutthugel von Vindonissa, Basel, 1952.
FERNÁNDEZ CHICARRO, C. Novedades en la Necrópolis romana de Carmona (Sevilla). Bellas Artes, 70, n ${ }^{\circ} 4,1970$, pág. 47 ss.

FORTUNATI ZUCCALA, M.: Gropello Cairoli (Pavia). La Necropoli romana, in Notizie degli Scavi, ser. VII, XXXIII, 1979, págs. 5-88.

GONZÁLEZ SIMANCAS, M. Excavaciones en Cartagena. MJSEA, 102. 1929.

GOUDINEAU, Ch. La ceramique Aretine Lisse. Melanges d'Archeologie et d'Histoire. Supléments 6. París, 1968.

GRATALOUP, C. Les céramiques á parois fines. Rue des Farges á Lyon. $B A R$ Inter. Series 457, 1988.

GRAUE, G. Die Gräberfelder von Ornavasso, Hamburgo, 1974.

HOLWERDA, J. H. Het Laat-grieksche en Romeinsche Gebruiksaardewerk uit het Middellandsche-Zee-Gebied in het Rijksmuseum van Oudheden te Leiden. S'Gravenhage, 1936.

ISINGS, C. Roman glass from Dated Finds. Groningen, 1957.

LAMBLOGIA, N. Quadro generale della cronologia delle necropoli e della evoluzione delle forme. Riv. Studi Liquri, IX, 2-3, 1943.

- Gli scavi di Albintimilium e la cronologia della ceramica romana, I, Bordighera, 1950.

LOBREGAT, M.; ROSSER, P. Un grafito bilingüe encontrado en la Albufereta (Alicante), y la pervivencia del sustrato indígena en la ciudad romana del Tossal de Manises. Arqueologia-Alicante 1987-1989. Excmo. Ayuntamiento de Alicante, 1990, en prensa.

LOESCHCKE, S. Keramische Funde in Haltern, ein Beitrag zur Geschichte der augusteischen Kultur in Deutschland, in Mitteilungen Attertumskommission für Westfalen, V. 1909, págs. 101-322.

- Lampen aus Vindonissa. Ein Beitrag zur Geschichte von Vindonissa und des antiken Beleuchtungswesens. Zurich, 1919.

- Die Römische und die belgische Keramik aus Oberaden, in CH. Albrecht; Das Römerlager in Oberaden, Vol. II. Dortmund, 1942.

LLOBREGAT, E. Datos para el estudio de las cerámicas ibéricas de época imperial romana. X. CNA, Mahón, 1969, págs. 366-378.

- Contestania Ibérica. Alicante. 1972.

- La conquista romana y el proceso de latinización, en Nuestra Historia, T. Il, pág. 37 ss. 1980.

- Las tierras valencianas hasta el final del principado de Augusto, en Nuestra Historia, T. II, pág. 47 ss. 1980.

MACCHIORO, S. Tomba romana da Zinasco (Pavia). Notizie dal Chiostro del Monastero Maggiore. Rassegna di studi del Civico Museo Archeológico e del Gabinetto Numismatico di Milano, XXXIII-XXXIV, 1984, págs. 11-25.

MANERA, E. Las cerámicas romanas de la necrópolis de «Sa Carrotja», Ses Salines (Mallorca). VI Symposium de Prehistoria Peninsular. Barcelona, 1974.

MARABINI, M. T. The Roman Thin-Walled Pottery from Cosa. Memoirs of the American Academy in Rome, XXXII, Roma, 1973.

MARTÍN ÁVILA, G. Terra sigillata de Liria. Rev. de Studi Liguri, XXIX, 1963, págs. 83-98.

MAYET, F. Parois fines et céramique sigillée de Ríotinto (Huelva), en Habis. I, 1970, págs. 139-176.

- Les ceramiques a parois fines dans la peninsule Iberique. Paris, 1975.

- Les ceraemiques sigillees Hispaniques. París. 1984.

MEZQUIRIZ, M. ${ }^{\circ}$, A. Terra sigillata hispánica. Valencia, 1961. 
NOBILE, I. I corredi della necropoli di Villa Soave: analisi e considerazioni. Storia di Capiago Intimiano, IV, Como, 1984, págs. 43-117.

NORDSTRÖM, S. La ceramique peinte iberique de la province de Alicante. Acta Universitatis Stockolmiensis, VIII, Estocolmo, 2 vols. 1973.

ORFILA, M. La necrópolis de Sa Carrotja y la romanización del sur de la isla de Mallorca. BAR Inter. Series 397. 1988.

OXE, A. y COMFORT, H. Corpus Vasorum Arretinorum. A Catalogue of the Signatures, Shapes and Cronology of Italian Sigillata. Bonn, 1968.

PARÍS, P. y BONSOR, Q. Fouilles de Belo (Bolonia, Cádiz). Tome II. La nécropole, pág. 119. Bourdeaux-París, 1923.

PASSI, L. Sub ascia, una necropoli romana a Nave. Ed. Panini. Modena, 1987.

PAVOLINI, C. Le lucerne nell'Italia romana, en Societá romana e produzione schiavistica, II. Merci, mercati e scambi nel Mediterraneo. 1981.

PONSICH, M. Les lampes romaines en terre ciute de la Mauritanie Tingitane. Publications du service de Antiquités du Maroc. Fas. 15. Rabat, 1961.

RAMOS FERNÁNDEZ, R. La ciudad romana de Illici. Alicante, 1975.

- Estratigrafía del Sector 5-F de la Alcudia de Elche. Lucentum $I I$, págs. 147-172. 1983.

RAMOS FOLQUÉS, A. Estado actual de las excavaciones en la Alcudia de Elche, VII $C N A$, págs. 273-277. 1962.

- Memorias de las excavaciones. Campañas realizadas durante los años 1956-1961. NAH VI, págs. 91 ss. 1962.

- Excavaciones en la Alcudia de Elche. Tr. Varios del SIP, $39,1970$.

RAMOS FOLQUÉS, A.; RAMOS FERNÁNDEZ, R. Excavaciones en la Alcudia de Elche durante los años 1968 a 1973. $E A E$, 91. Madrid. 1976.

REMESAL RODRÍGUEZ, J. La necrópolis Sureste de Belo. $E A E, 104$. Madrid, 1979.

RICCI, A. Settefinestre. Una Villa Schiavistica nell, Etruria romana. 2 La villa e i suoi reperti. Ed. Panini. 1988.

RITA, C. La necrópolis romanas de Mahón-Menorca. Institut d'Estudis Baleárics. Palma, 1982.
ROCA ROUMENS, M. Sigillata Hispánica producida en Andújar (Jaén). Publ. Inst. Estudios Giennenses. Jaén, 1976.

RODRÍGUEZ OLIVA, P. La Arqueología romana de Algeciras (Cádiz), en Segovia y la Arqueología Romana. Universidad de Barcelona, 1977, pág. 345 ss.

ROS SALA, M. ${ }^{a}$ MILAGROSA: La pervivencia del elemento indígena: la cerámica ibérica. Universidad de Murcia, 1989.

ROSSIGNANI, M. P. Unguentari, in Scavi di Luni, 1973, pág. 355.

ROSSER LIMIÑANA, P. Últimos descubrimientos arqueológicos en Historia de Alicante, fasc. 6, El Tossal de Manises y su entorno. Excmo. Ayuntamiento de Alicante, 1989.

ROVELLI, G. Ceramica comune: olpai. Angera romana. Scavi nella necropoli 1970-1979. Roma, 1985, págs. 427-450.

SACCARDO, L. Cerámica comune: urne e ciotolo-coperchio, in Angera romana. Scavi nella necropoli 1970-1979, Roma, págs. 469-85. 1985.

SÁNCHEZ, M. J.; BLASCO, E.; GUARDIOLA, A. Portus Illicitanus. Datos para una síntesis. Ayuntamiento de Santa Pola, 1986.

SENA CHIESA, G. Scavi dell'Universitá degli Studi di Milano nella necropoli romana di ANGERA (Campagne 1975-1978). Osservazioni preliminari, en $A C M E$, XXXXII, 1979, págs. 37-79.

SIMONETT, C.; LAMBOGLIA, N. Necropoli romane nelle terre dell'attuale Canton Ticino. Archivio Storico Ticinese, Bellinzona, 1967-1971.

THOMPSON, H. A. Two Centuries of Hellenistic Pottery. HESPERIA, 3, 1934.

VEGAS, M. Römische Keramik von Gabii (Latium). Bonner Jahrbücher, 168. 1968, pág. 13 ss.

- Cerámica común romana del Mediterráneo Occidental. Publicaciones eventuales, 2. Instituto de Arqueología y Prehistoria de la Universidad de Barcelona. Barcelona, 1973.

- Mulva II. Die Südnekropole von Munigua grabungskampagnen 1977 bis 1983. Madrider Beiträge. Band 15. 1988.

ZEVI, F.; PHOLI, I. Ostia (Roma). Caserma dei vigili. Scavo sotto il mosaico del vano antistante il «Cesareo». Casa delle pareti gialle, salone centrale. Scavo sotto il pavimento a mosaico. NSA. 1970. 